\title{
A Study on Establishment of Heyuan Wisdom Tourism System ZHU Zhi ${ }^{1, a}$ \\ ${ }^{1}$ Heyuan Polytechnic, Heyuan, Guangdong, China \\ azhuzhi007@126.com
}

Keywords: wisdom tourism; Heyuan; System

\begin{abstract}
The core service object of wisdom tourism system is the tourists, and tourism large data centers is the basis of the construction. This paper expounds the connotation of wisdom tourism, the architecture of it, and then analyzes the development of Heyuan wisdom tourism, finally puts forward the countermeasures and Suggestions to develop the wisdom tourism.
\end{abstract}

\section{河源市智慧旅游体系构建研究}

\author{
朱智 $1, a$ \\ 1河源职业技术学院, 河源, 广东, 中国 \\ azhuzhi007@126.com
}

关键词：智慧旅游；河源；体系

摘要: 智慧旅游体系的核心服务对象是游客, 旅游大数据中心是其建设基础。本文阐述了智慧 旅游的内涵、智慧旅游体系架构, 分析了河源市智慧旅游发展的现状及存在的问题, 最后提 出了发展智慧旅游的对策与建议。

\section{1. 引言}

随着旅游业的迅猛发展, 旅游者的需求越来越个性化、多样化, 散客旅游的时代已经来 临。特别是现代信息技术、云计算、互联网、物联网与旅游业的结合，人们更热衷于通过电 脑、手机在线预定旅游产品, 线下体验旅游产品。据艾瑞网咨询统计, 2013年中国在线旅游 市场交易规模 2204.6 亿元, 同比增长 $29.0 \%$ 。预计 2017 年市场规模 4650.1 亿元, 复合增长率 $20.5 \%$ 。因此, 基于游客需求旅游信息的智慧旅游体系建设刻不容缓。近年来, 我国也非常重 视智慧旅游的建设与发展，国家旅游局将2014年定为 “中国智慧旅游年”，北京、西安、武 汉、杭州等城市已经试点进行智慧旅游发展与建设, 并取得了良好成效。智慧旅游已成为了

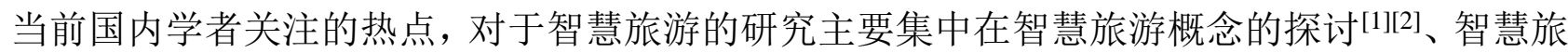

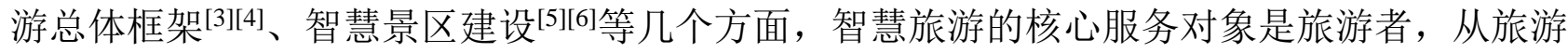
者的角度建设智慧旅游体系才能真正满足他们的需求, 帮助他们完成旅游体验, 才是真正的 智慧旅游。本研究以游客的视角来审视未来旅游目的智慧旅游体系建设, 并以广东河源市智 慧旅游建设为例, 构建其智慧旅游体系, 满足游客的需求, 期望为未来优秀旅游城市智慧旅 游的发展提供新思路和新方法。 


\section{2. 智慧旅游的内涵}

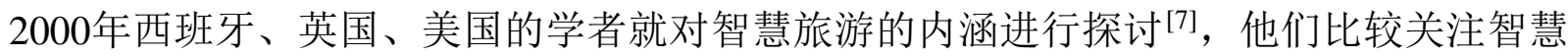
旅游与可持续旅游发展的关系, 认为智慧旅游是深层次的游客参与、旅游目的地与游客的深 度融合、旅游企业从中获利点, 智慧旅游应为旅游业带来更多的利益, 较少将其作为旅游业 发展的核心。我国将智慧旅游作为旅游业发展的核心, 国内多数学者认为智慧旅游就是利用 云计算、物联网等新技术, 通过互联网/移动互联网, 借助便携的终端上网设备, 主动感知旅 游资源、旅游经济、旅游活动、旅游者等方面的信息, 及时发布, 让人们能够及时了解这些 信息, 及时安排和调整工作与旅游计划, 从而达到对各类旅游信息的智能感知、方便利用的 效果。它关注的重点是借助新的信息技术，而忽略了智慧旅游的核心服务对象一一旅游者。 本研究认为智慧旅游的核心服务对象是旅游者, 政府、旅游企业、旅游协会等通过对游客旅 游信息需求的调查与分析后, 将符合旅游者需求的旅游资源、旅游促销、旅游活动、天气、 旅游交通、旅游纪念品、旅游评价、旅游感受等旅游信息分门别类及时的发布到云平台、互 联网/移动互联网, 让游客准确、及时、有效的了解这些信息, 无需进行再次的分析与甄别从 而进行线上线下的旅游交易, 最终实现智慧旅游。

\section{3. 智慧旅游体系的构建}

据中国互联网络发展状况统计，截至2014年6月，我国网民规模达6.32亿人，其中手机网 民规模达 5.27 亿，手机上网使用率达 $83.4 \%$, 首次超越传统PC整体使用率 $(80.9 \%)$ 。据统计在 网上预定过机票、酒店、火车票或旅行行程的网民规模达到 1.90 亿。半年内, 网民在线旅行 预订的比例从 2013 年的 $29.3 \%$ 提升至 $30.0 \%{ }^{[8]}$ 。互联网时代, 游客获取旅游信息的方式发生着 巨大的变化。从某种意义上来说, 优质的旅游信息是旅游者进行旅游决策出行的助推器。国 内的大多数自助旅游者都是从旅游网站来搜集、查询旅游目的地、旅游景区的信息, 多数旅 游网站的旅游信息能满足游客的需求, 但是存在信息陈旧、杂乱, 游客需要大量的时间去伪 存真, 从侧面说明这些旅游信息的内容并没有去调查与研究游客的偏好与要求, 没有进行分 析与技术处理, 游客的满意度较低。虽然, 游客对于旅游信息的需求还是主要集中于 “吃”、 “住”、“行”、“游”、“购”、“娱”，但是需求的形式与内容发生了变化。而这些信 息的提供又给政府部门、旅游企业提出严峻的要求, 需要他们调研、了解游客的需求变化, 并及时、准确、分门别类的上传到旅游信息平台，游客通过便携的上网终端来获得这些信息。 智慧旅游体系的核心内容是服务, 服务的对象是旅游者, 政府、旅游企业是旅游信息的提供 者, 三者之间建立良好的互动关系, 才能完全发挥智慧旅游的功能, 真正实现智慧旅游（见 图1）。

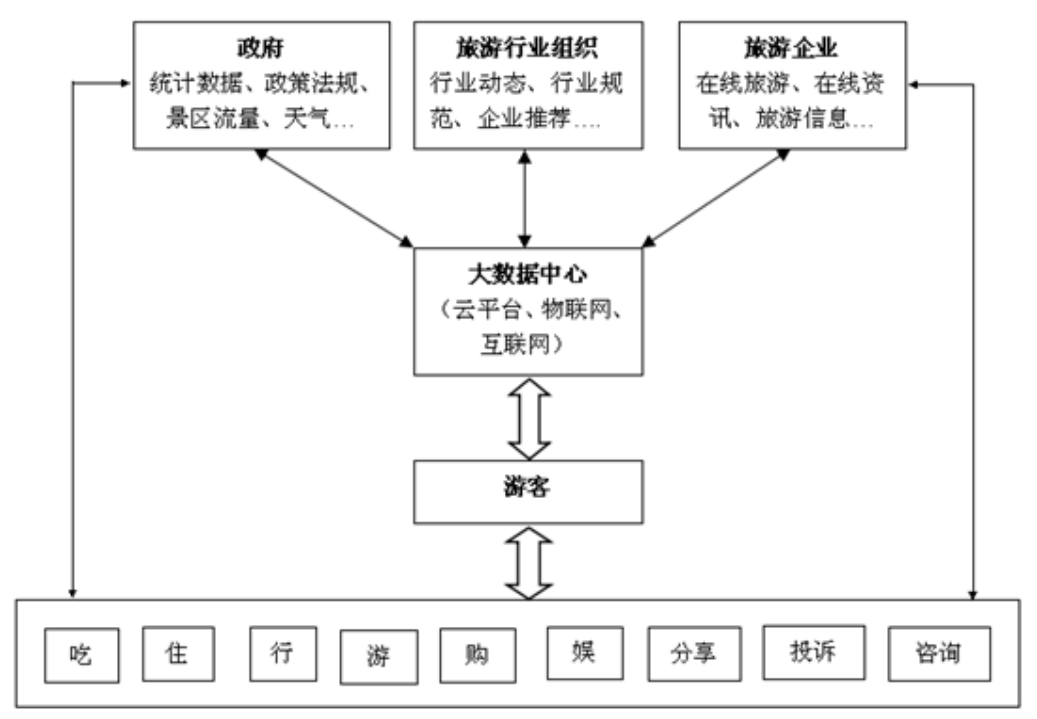

图1 智慧旅游体系构建示意图 


\section{1 智慧旅游体系的核心服务对象一一游客}

智慧旅游体系的构建目标是让所有到达旅游目的地的游客能顺利完成包含旅游六要素在 内的旅游全过程, 并能及时的评价、分享他们的旅游过程、旅游经历, 从而为其他的游客提 供参考与帮助。散客、自助游是未来旅游发展的趋势，他们对于旅游信息的需求非常渴望。 未来旅游信息的内容不仅仅局限在 “吃”、“住”、“行”、“游”、“购”、“娱”这六 个方面, 同时更加需要其他游客的旅游评价、旅游投诉、旅游经验、旅游日志等。因此, 未 来游客的旅游信息需求是智慧旅游体系中需要重点建设的内容, 它建立的最终目标就是让游 客能借助相关智慧旅游设施、智能终端、移动终端等帮助他们实现智慧旅游, 满足他们的需 求。

\section{2 智慧旅游体系的建设基础一一大数据中心}

智慧旅游体系的根基是旅游大数据中心的建设，也是旅游信息化发展的必然趋势。以往 政府、企业、协会等发布和存储的旅游IT数据具有多样性的特点, 互相之间不能共融, 存在 重复建设的问题, 游客获取的信息不准确, 也缺乏权威性。大数据中心的存在能将各种类型 的数据进行规范化的处理和存储，对同类资源、信息、业务能进行整合，改变旅游行业各部 门之间各自为政的现状。数据中心的建设可以划分为 5 个子系统, 分别为数据获取系统、数据 存储系统、数据安全系统、灾难恢复及业务连续性系统、数据挖掘与决策支持系统 ${ }^{[9]}$ 。

表1 旅游大数据中心 5 大子系统功能 ${ }^{[9]}$

\begin{tabular}{ll}
\hline \multicolumn{1}{c}{ 子系统名称 } & \multicolumn{1}{c}{ 主要功能 } \\
\hline 数据获取系统 & 将酒店、旅行社、旅游资源等电子化与纸质化的信息采用规范 \\
& 的格式录入数据中心 \\
& 对所有的信息进行统一格式存储, 分门别类, 统一管理, 标准 \\
数据存储系统 & 化发布, 采用动态存储池技术, 能自动扩容。 \\
数据安全系统 & 保护数据中心不受病毒、黑客破坏 \\
灾难恢复及业务连续性系统 & 建立了完备数据恢复的预警系统预案, 避免数据的丢失。 \\
& 对用户的各种指定信息进行汇总、统计和分析。依据信息资源 \\
数据挖掘与决策支持系统 & $\begin{array}{l}\text { 规划所梳理出的基础指标库的内容, 从行业的各个业务系统 } \\
\end{array}$ \\
& 中抽取、转换、加载, 到数据中心的规范数据库中。 \\
\hline
\end{tabular}

\section{4. 河源市智慧旅游的发展现状}

河源市位于广东省东北部，为中国优秀旅游城市。近年来，河源旅游发展迅速，2015年 接待入市游客 1905.1 万人次, 旅游总收入 152.6 亿元。但是, 河源智慧旅游的发展刚刚起步。 2012年河源市政府与广东联通签约 “智慧河源” 战略协议。随后, 河源联通与五县一区政府 成功签约，双方达成共识：建设 “智慧河源” 旨在依托新技术，树立中国联通的城市信息化 新形象, “智” 于管理, “慧” 及民生, 促进应用创新及可持续发展, 整合产业链, 发挥协 同效应。“十二五” 期间，广东联通在河源规划投资8亿元，打造WCDMA3G精品网络及宽 带高速网络，促进物联网、云计算的示范应用。这些与智慧河源相关的手机客户端的开发对 于河源智慧旅游体系建设打下了良好的基础。但是，这些手机客户端的开发彼此之间缺乏一 定的联系，在某些模块的设置中存在雷同的问题。对于不同客户端统计与收集信息基本没有 经过处理和编码，更新不及时，因而真正使用的用户还是非常有限。对于河源相关的海量旅 游信息、政府信息、经济资料等缺乏整理与分类，特别是对于河源居民与到河源旅游的游客 的旅游需求统计与分析数据为零, 然而这些数据对于智慧旅游相关客户端的开发至关重要, 决定着能否实现智慧旅游。

\section{5. 河源市智慧旅游体系建设对策}

（1）构建河源市智慧旅游体系框架。智慧旅游体系的核心服务对象是游客，基础是旅游 大数据中心的建设。因此, 河源市智慧旅游体系的建设重点一个是基于游客感知的旅游信息 
数据收集与整理, 另外一个是基于物联网、互联网、云计算为基础的大数据中心平台。旅游 大数据中心平台的建设需要河源市政府与中国联通共同承担建设责任, 将旅游相关部门的数 据经过专业部门、专业人员的整理与分析, 进行统一的编码录入到数据库。其中与旅游相关 的手机客服端、旅游电子商务网站的建设应融合在一起，避免重复开发造成资源浪费。

（2）加强企业与政府信息化建设。当前河源市旅游企业、政府的信息化建设程度不高， 这也导致旅游景区、酒店等企业与智慧旅游体系对接不上。许多旅行社、旅游景区建设了网 站, 但是网站的内容乏善可陈, 信息陈旧, 在线服务滞后, 不能进行在线的交易支付, 缺乏 特色。虽然旅游企业意识到了旅游电子商务、在线服务、数字化管理、网络营销的重要性, 但是在实际的执行过程中不彻底，没有资金、没有技术人员的支撑。智慧旅游体系是一个庞 大的数据库, 它是由许多信息化建设良好的旅游企业电子商务网站、政务网站所组成的, 智 慧旅行社、智慧酒店、智慧景区、智慧交通、智慧政府是建设智慧旅游体系的基础。

（3）积极推进智慧旅游体系的建设工作。2012年12月，国家旅游局在全国智慧旅游建设 会上，提出争取在10年内初步实现 “智慧旅游” 的总体目标。智慧旅游的建设对河源市旅游 业乃至河源市的发展都具有重要的意义。在智慧旅游体系的建设过程中, 政府要发挥积极推 动的作用, 大力宣传智慧旅游, 积极推进旅行社、旅游景区、酒店的智慧建设, 让企业认识 到智慧旅游对旅游发展的重要性, 让智慧旅游的概念深入人心, 让所有到达旅游目的地的游 客及本地居民实现智慧旅游, 从而不断进行良性的 “口碑效应” 循环, 推动智慧旅游, 从而 推动智慧城市的发展。

\section{致谢}

本文为2014年广东省高等学校优秀青年教师培养计划项目部分研究成果之一。

\section{References}

[1]ZHANG Lingyun, LI Nao, LIU Min, On the Basic Concept of Smarter Tourism and Its Theoretical System, Tourism Tribune, vol.27, pp. 66-73, 2012.

[2]LI Yunpeng, Clark HU, HUANG Chao, et al, The Concept of Smart Tourism under the Context of Tourism Information Service, Tourism Tribune, vol.29, pp. 106-115, 2014.

[3]Chen Yan, LU Yiwei, A study on "wisdom tourism" system framework of the local government of huaian in Jiangsu, Journal of Jilin TV \& Radio University, vol.2, pp. 136-137,2015.

[5]YAO Guozhang. A study on the construction framework of intelligent tourism, Journal of Nanjing University of Posts and Telecommunications(Social Science),vol.2, pp.13-16, 2012,

[6]WENG Gangming, LI Weijing, Smart Tourism and the Innovative Mode Establishment of Regional Tourism Development in Qinhuangdao, Urban Development Studies,vol. 5, pp.35-38, 2014.

[7]DANG Anrong, ZHANG Danming, CHEN Yang, Study on the Essential Concept and General Framework of Smart Famous Scenic Site, Chinese Landscape Architecture, vol. 9, pp. 15-21, 2011.

[8]34 times China Internet network development state statistic report, China Lnternet, vol. 7, pp, 71-89, 2014.

[9] LIU Zhihua, Data Center Construction of Beijing Tourism Industr, Business Economy, vol. 1, pp. 60-62, 2013. 